\title{
PREDATOR VIGILANGE COSTS OF ALLOGROOMING IN WILD BLUE MONKEYS
}

\author{
by \\ MARINA CORDS ${ }^{1,2}$ ) \\ (Anthropology Department, Columbia University, New York, NY 10027, U.S.A.)
}

(Acc. 29-III-1995)

\begin{abstract}
Summary
Although allogrooming in Catarrhine primates is often interpreted as if it were a costly behavior for the groomer, such costs have not been convincingly documented. This paper presents data on rates of vigilance for aerial predators, measured as looking up toward the sky, in wild blue monkeys engaged in allogrooming, and compares these vigilance rates to those occurring when the same individuals engaged in other activities, namely feeding and resting. Grooming individuals have much lower vigilance rates than resting or feeding individuals, suggesting that grooming individuals are more likely to be at risk of being preyed upon. These results are not caused by a systematic relationship in the sample between activity and either foliage density or time of day, two factors potentially related to levels of safety from predation. Nor was there evidence that blue monkeys avoid the vigilance costs of grooming by engaging in this behavior primarily at safe times or in safe locations. Although the data suggest that vigilance costs occur, they may accrue to the recipient of grooming as well as the groomer, and may be compensated for both partners by long- or short-term benefits.
\end{abstract}

\section{Introduction}

In studies of Catarrhine primates, the frequency and patterning of allogrooming are often taken to reflect patterns of affiliation (e.g. LiNDburg, 1973) or social strategies (e.g. Stammbach \& Kummer, 1982) of the individuals involved. Grooming is interpreted as an investment in a social relationship (e.g. Dunbar, 1988), and analyses of grooming thus figure prominently in discussions of the evolutionary basis of social exchange. For example, grooming has been taken to exemplify altruistic behavior in primates, and its patterning has been examined to see whether the

\footnotetext{
1) e-mail:mc51@columbia.edu

2) I am grateful to the government of Kenya for permission to study blue monkeys in the Kakamega Forest, to the University of Nairobi Zoology Department for local sponsorship, to Columbia University for partially subsidizing this particular project, and to Hanspeter Schaub and an anonymous reviewer for comments on the manuscript.
} 
theories of kin selection (KuRLANd, 1977; SilK, 1982) or reciprocal altruism (Seyfarth \& Cheney, 1984; Hemelrijk, 1994; Muroyama, 1994) can satisfactorily explain its occurrence and patterning in these animals.

For a behavior to be considered altruistic, it must be associated with some cost to the performer, as well as a benefit to the recipient. These costs and benefits may be essentially immediate, or they may be longterm. Goosen (1981) summarized various potential benefits of allogrooming to the recipient, and recent empirical research directly supports the ideas that recipients benefit immediately in terms of improved hygiene (Barton, 1985; Tanaka \& Takefushi, 1993) and stress reduction (Schino et al., 1988; Boccia et al., 1989).

Costs of grooming for the actor, however, have received less convincing empirical support (Dunbar, 1988; Maestripieri, 1993; Schaub, 1994). Immediate costs that have been attributed to groomers include energetic costs, time or opportunity costs (especially reduced foraging time) and the possibility of medical complications or even death from the build-up of hair boluses in the cecum (Silk, 1982; Kurland, 1977; Muroyama, 1994). Although at least some of these costs of grooming are widely cited or assumed (e.g. Silk, 1987; Muroyama, 1994), there is little evidence that any of them is significant in natural populations. Energetic costs have been estimated by analogy to human activities, and appear, on a per minute basis, to be about as low as or lower than other activities that might occupy similar lengths of time, such as resting, feeding or moving (Coelho, 1986; Coelho \& Bramblett, 1989). In baboons and geladas, extra time spent grooming is not associated with reduced foraging time, but instead with reduced resting time (Dunbar \& Sharman, 1984): the lack of trade-off of grooming and foraging time suggests that foraging opportunity costs also do not apply. Hair boluses are a problem only in laboratory animals maintained on diets unnaturally low in fiber (GREENBERG, 1970).

More recently, MAEsTRIPIERI (1993) identified a different sort of immediate cost to groomers resulting from reduced vigilance, an automatic consequence of the visual attention that grooming requires of its practitioners. His study of captive rhesus macaque females documented reduced maternal vigilance associated with increased harrassment of infants as a consequence of grooming. He argued that harrassment of infants, especially under more naturalistic conditions, would likely dimin- 
ish their chances of survival. While the data are compelling, it is difficult to judge how universal this cost of grooming might be. First, it is conceivable that rates of infant harrassment would be lower in wild, non-provisioned populations in which animals spend more time foraging and are not forced into proximity. Second, this cost of grooming applies only to mothers. Finally, there may be differences among species in the likelihood of infant harrassment (MAEstripieri, pers. comm.), and hence variation across primates in the relevance of the proposed cost.

In the discussion of his results, MaEsTRIPIERI alluded to a related cost of allogrooming by suggesting that grooming may also reduce vigilance for predators. This hypothesis was suggested by Hart et al. (1992) with respect to self-grooming in antelope, and the notion of a trade-off between vigilance and allogrooming has also been considered by ISBELL \& Young (1993) in a study of vervet monkeys. Rose \& Fedigan (1995) demonstrated that vigilance levels of adult capuchin monkeys were negatively associated with affiliative behavior (which included grooming and resting in contact). Because nearly all primates face some threat from natural predators, a predator vigilance cost is potentially applicable to more classes of individuals and to more species than a maternal vigilance cost. The purpose of the present study was to evaluate the hypothesis that in wild, unprovisioned monkeys, grooming is associated with reduced vigilance for aerial predators.

\section{Methods}

The subjects of this study were wild blue monkeys (Cercopithecus mitis stuhlmanni) inhabiting the Kakamega Forest, western Kenya (see Coros, 1987 for a description of this rain forest site). Blue monkeys are primarily arboreal primates that live in female-bonded groups typically including 15-45 individuals. During the non-breeding scason, only one of the group members is an adult male; roughly one third to one half of group members are adult females, and the remainder are immatures under the age of about 6 years. The data on vigilance reported here were collected during the breeding season, when 1-4 adult males accompanied the females and their offspring (see Cords, 1988).

The subjects were members of two habituated social groups ( $T w$ and $G$ ), with 31 and 32 members respectively. These animals were observed from July-September 1994. All subjects were adult females or juveniles of either sex. Adult males were not included as subjects because they rarely groom, and because their vigilance behavior was likely to be directed not only toward potential predators, but also to other adult males (who are competitors for mates). All subjects were individually recognized. Data from the two groups were combined, since no between-group differences were found. The analysis is limited to 31 individuals who were monitored while they engaged in all three sampled activities (see below): these animals included 23 adult females, 5 juvenile females, and 3 juvenile males.

The three activities that monkeys engaged in, and during which their vigilance behavior was monitored, included feeding, resting, and grooming. Feeding included ingestion, 
processing, harvesting or looking for food; each sample included at least one instance of ingestion, and usually many more than one. Resting consisted of the subject sitting or lying without moving, feeding or grooming. If a sitting animal briefly stood up, but did not take more than one step or engage in any additional activity, it was still counted as resting. Grooming subjects were the active partners in a grooming bout.

Feeding and resting were chosen as control activities for comparison with grooming because they account for the largest portion of an animal's time, and are thus representative of its general activity: among 15 females, an average of $54 \%$ of time was spent feeding, while $31 \%$ of time was spent resting (CorDs, unpublished). Another major activity category is moving, which accounts for an average of $9 \%$ of an animal's time; however moving could not be used as a control activity because it was not possible, given the observation conditions, to monitor vigilance levels of moving animals. Because moving animals are likely to be more vigilant than resting or feeding animals, however, any reduction in vigilance associated with grooming would be even more marked if moving had been used as a control.

Observations were made from paths on the forest floor, usually with the aid of $10 \times 40$ binoculars. Because of limited visibility in the forest, subjects were selected opportunistically as focal animals, but no individual was sampled more than once on a given day. For each subject, observations were made during 3 one-minute periods: one when the subject was feeding, one when it was resting, and one when it was grooming. Samples in which the subject switched activities before 50 seconds had elapsed, or in which the subject became invisible to the observer, were aborted and discarded. In each counted sample, the predominant activity (either feeding, resting or grooming) lasted at least 50 seconds, and usually lasted the entire one-minute period. In 8 exceptional cases, the predominant activity was interrupted by a few seconds of a different activity in the last $10 \mathrm{sec}$ of the sample. It was not possible to monitor the duration of these interruptions along with vigilance levels, and all samples were analyzed as if they had lasted one full minute.

The main predator of these monkeys is the crowned hawk eagle (Stephanoaetus coronalus), a large raptor that swoops down into the group when making an attack (CoRDs, 1987; LeLand \& Struhsaker, 1993). The monkeys respond by dropping into the cover of dense foliage while making alarm calls. Eagles also elicit alarm responses when they fly directly above the forest canopy over a monkey group, and sometimes when they cngage in a flying and calling display high above the canopy. Vigilance was measured accordingly as the number of times a subject looked up toward the sky. A previous study showed that the frequency of such looking up was inversely correlated with the foliage density surrounding the subject, suggesting that the behavior scored did reflect levels of predation risk, and hence was an appropriate measure of vigilance for aerial predators (CoRDs, 1990).

In addition to data on looking up, the time of day of the sample and the foliage density surrounding the subject were recorded. Foliage density was categorized as high, medium or low, as described by CoRDs (1990). This information was used to evaluate whether any effects of activity type on rates of looking up might have resulted from a correlation in the sample between activity and either foliage density or time of day.

The data on looking were up were analyzed using non-parametric tests, as they failed to be normally distributed even when transformed. Friedman analysis of variance was used to test for differences in vigilance levels across activities; where results were significant, pairwise multiple comparisons between the different activity classes were made as described in Siegel \& Castellan (1988, p. 180).

The analysis of vigilance levels as a function of activity suggested the possibility that monkeys might compensate for vigilance costs while grooming by engaging in this activity only when it was safe. An earlier study (Cords, 1990), showing that vigilance was inversely correlated with foliage density, suggested specifically that grooming might be more likely than other activities to occur when surrounding foliage density was high. To test this hypothesis, data were needed that related the performance of different activities to other 
conditions related to safety, such as foliage density or time of day. Although some such data were gathered in this study, they were too sparse to reflect accurately the conditions under which the different activities normally occurred; therefore, additional data were analyzed. These data came from continuous focal samples of 15 large juvenile and adult female blue monkeys in the Tw group, collected for 11 hours per individual from June-August 1993. For all individuals, samples were spread out over the day. Focal samples lasted one hour, and included transition times (to the nearest second) between major classes of activity as well as transition times between different trees occupied by the subjects. For the purposes of this paper, only feeding, resting and grooming were analyzed. The foliage densities in which these activities occurred were not noted at the time of sampling, but were assigned after the fact by matching a foliage density class (high, medium, low, as above) to each tree species in which the subjects were observed. The assignment of typical foliage densities to each tree species was based on my knowledge of the trees at this site, gained over 15 years of field work. The assignment was made independent of information on what activity a subject was engaged in while occupying a particular tree species. This is undoubtedly a crude way to assess foliage density, because individual trees of a given species, and even different parts of individual trees, may vary in terms of the foliage density surrounding a particular animal. However, because only tree identity, rather than foliage density, was explicitly monitored during these focal samples (which, in contrast to the vigilance data, were originally collected for other purposes), this was the only possible way to estimate the amount of time spent in different foliage densities as a function of activity.

\section{Results}

Vigilance levels and activity.

Vigilance levels varied significantly across different activities (Table 1, Friedman analysis of variance, Chi-squared (corrected for ties) $=41.28$; $\mathrm{df}=2$; 2-tailed $\mathrm{p}<0.0001$ ). In particular, grooming monkeys showed significantly lower vigilance levels than either feeding or resting monkeys (2-tailed $\mathrm{p}<0.05)$. Monkeys engaged in the latter two activities showed no significant differences in vigilance levels.

In view of results from a previous study (Conds, 1990), which showed that vigilance levels were lower for subjects in higher foliage densities, it is important to demonstrate that the present results were not caused by a systematic relationship between activity and foliage density in the sample analyzed. The analysis was therefore repeated omitting those individuals

TABLE 1. Vigilance level as a function of activity

\begin{tabular}{lccc}
\hline & Feeding & Resting & Grooming \\
\hline Mean number of look-ups & 3.19 & 3.07 & 0.45 \\
Standard deviation & 1.30 & 1.09 & 0.77 \\
Range & $1-6$ & $0-5$ & $0-3$ \\
\hline
\end{tabular}

$\mathrm{N}=31$. 
who were observed grooming in a site with a higher foliage density (where one would thus expect lower vigilance levels) than those sites where it was observed feeding or resting. This analysis of 19 individuals gave exactly the same results as the full sample (Chi-squared (corrected for ties) $=$ 23.05; $\mathrm{df}=2$; 2-tailed $\mathrm{p}<0.0001 ; 2$-tailed $\mathrm{p}<0.05$ for the contrasts between grooming and each of the other activities).

Another possible explanation for the results could be that grooming (and an associated reduction in vigilance) occurs at times of day when eagle attacks are less likely. The likelihood of eagle attacks in this population does not vary significantly over a diurnal time scale, although some variation was observed (CoRDs, 1987). This variation served as a basis for re-analyzing a subset of the present data; in particular, individuals were omitted if their grooming was monitored during a 2-hour period in which eagle attacks had been observed to be less frequent than in the 2-hour periods in which either feeding or resting were monitored. (For this purpose, the day was divided into 6 2-hour periods, from $0700-1900 \mathrm{~h}$ ) This analysis of 18 individuals also gave exactly the same results as the full sample (Chi-squared (corrected for ties) $=23.86$; $\mathrm{df}=2 ; 2$-tailed $\mathrm{p}<$ $0.0001 ; 2$-tailed $\mathrm{p}<0.05$ for the contrasts between grooming and each of the other activities). In sum, the reduced vigilance levels shown by grooming monkeys did not seem to result from a systematic relationship in the sample between activity and either foliage density or time of day; rather, vigilance differences appear to relate to activity type per se.

Activity and foliage density.

Although monkeys may be less vigilant when grooming, the effective costs of such reduced vigilance could be minimal if grooming usually occurred under conditions when predation risk were minimal. Table 2 shows the

TABLE 2. Mean percentage of time spent in trees with different foliage densities, according to activity

\begin{tabular}{lccc}
\hline Foliage density & Feeding & $\begin{array}{c}\text { Activity } \\
\text { Resting }\end{array}$ & Grooming \\
\cline { 2 - 4 } & 4.7 & 12.1 & 9.1 \\
low & 82.6 & 61.3 & 61.3 \\
medium & 12.7 & 26.5 & 29.6 \\
\hline
\end{tabular}

$\mathrm{N}=15$ individuals, each contributing 11 hours of focal time. 
percentage of time (averaged across 15 fully grown females who contributed to continuous focal animal samples in 1993) spent in trees with different foliage densities according to activity category. These data do not support the hypothesis that grooming is more likely than other activities to occur in relatively safe locations, i.e. in trees with high foliage densities. Although the percentage of time spent grooming, feeding and resting in trees with high foliage density differed significantly (Friedman analysis of variance, Chi-squared $=6.533 ; \mathrm{df}=2 ; 2$-tailed $\mathrm{p}=0.0381$ ), the only significantly different pairwise comparison occurred between resting and feeding $(2$-tailed $\mathrm{p}<0.05)$; the percentage of time spent grooming in trees with high foliage density did not differ significantly from the percentage of time spent either feeding or resting there.

\section{Discussion}

The data presented here show that when blue monkeys are engaged in allogrooming, they look up toward the sky less than when they are engaged in other activities such as feeding or resting. Insofar as looking up to the sky represents vigilance for aerial predators, this result suggests that grooming may be costly for its practitioners in terms of avoiding predation. This reduction in vigilance levels while grooming did not occur because grooming was sampled in locations or at times characterized by lower predation risk.

Predator attacks are too rare in this population to show explicitly that the observed reduction in vigilance is associated with a measurable cost in terms of increased mortality. However, other observations linking behavior associated with vigilance to mortality support the reality of such a cost. For example, Struhsaker \& Leakey (1990) analyzed the species and age-sex class composition of the monkey prey of crowned hawk eagles in the Kibale Forest, Uganda. They related selectivity by the eagle to the degree to which prey species participated in mixed species groups with communal vigilance, and to the degree to which certain age-sex classes (namely males) lived outside of social groups, and so lacked the greater communal vigilance that such groups provide. Similarly, Gautier-Hion et al. (1983) reported that 3 of 4 observed successful attacks by crowned hawk eagles on Cercopithecus monkeys in Gabon occurred when the prey were in single-species groups, and thus lacked the additional eyes and ears for vigilance that life in mixed-species groups affords. In comparing the 
effects of mixed-species association on mortality to the present results, it is worth noting that changes in vigilance levels across activities appear to be substantially larger than changes in vigilance levels associated with participation in mixed-species groups. For the Kakamega blue monkeys, the vigilance level of grooming monkeys is about $15 \%$ of the vigilance level of resting or feeding monkeys; the vigilance level of a group of blue monkeys unassociated with redtails, however, is about $94 \%$ of the vigilance level of a mixed-species group (data from Conds, 1990, which included only feeding animals). If these relatively modest differences in vigilance levels between single- and mixed-species groups can lead to obvious differences in mortality among their members, then the much larger differences in vigilance levels associated with different activities are even more likely to have considerable consequences in terms of mortality risk. The magnitude of differences between effects of activity and effects of association with other species on vigilance levels may be somewhat exaggerated, however, because the degree of inter-individual synchrony in activity has not been taken into account: insofar as the activities of individuals are not synchronized, group vigilance levels could remain rather constant, despite large variation according to the activity of individual group members. At present, there are no data that link differential mortality and vigilance rates of individuals.

Although the analyzed sample of monkeys engaged in various activities was not biased in terms of predation risk, it remains possible that monkeys compensate for the increased risk associated with allogrooming by engaging in this behavior primarily at times or in locations where risk is minimized; if so, they would not actually incur a vigilance cost while grooming. Lima \& Dill (1990) have reviewed evidence that many animals adjust their behavior in response to varying degrees of predation risk. In this population, diurnal variation in predation risk is not significant, so it seems unlikely that adjustments in the timing of grooming could compensate for variable risk. However, monkeys might choose to groom in relatively low-risk locations, thereby compensating for their lower vigilance levels. The data from this study indicate that such compensation does not occur with respect to foliage density. It is possible that this apparent lack of compensation reflects limitations in the way risk was assessed: the method of assessing foliage density was indirect, and factors other than foliage density, such as height in the canopy, might also 
influence vulnerability to predators. There may also be social factors, such as competition for grooming partners, that limit when and where grooming bouts occur. Further investigation is called for.

As pointed out by MAEstripieri (1993), the existence of a vigilance cost to grooming does not completely clarify the picture of this behavior as altruistic because additional costs and benefits need to be considered. Such costs and benefits may be immediate, or may be long-term. In general, immediate consequences of grooming have been investigated more thoroughly than the long-term consequences, but the latter, including the effects of grooming on the social relationships of the grooming partners themselves, or on their respective relationships with third parties, are often assumed. It remains difficult to combine costs and benefits not only because their currencies differ, but also because they occur on very different time scales.

A further complication results from the fact that groomer and recipient may share some of the same costs and benefits. With respect to the shortterm cost of reduced vigilance reported here, I noted during observations that the recipient of grooming generally appeared to be even less vigilant than the groomer: the recipient was often in a posture that precluded vigilance (e.g. forequarters lowered, eyes directed down), or had its eyes closed. Thus the recipients of grooming may incur vigilance costs that are at least as great as those incurred by the groomer. Given the prevalence of allogrooming in many Catarrhine species, however, it seems likely that both groomer and recipient gain a net benefit from participating in this behavior, at least over the long run. If so, vigilance costs are probably small relative to the various benefits that they can gain.

\section{References}

Barton, R. (1985). Grooming site preferences in primates and their functional implications. - Int. J. Primatol. 6, p. 519-532.

Boccia, M.L., Reite, M. \& Laudenslager, M. (1989). On the physiology of grooming in a pigtail macaque. - Physiol. Behav. 45, p. 667-670.

Coelho, A.M. (1986). Time and energy budgets. - In: Comparative primate biology, Vol. 2, Part A: Behavior, conservation and ecology. (G. Mitchell \& J. ERwin, eds). Alan R. Liss, Inc., New York.

- \& Bramblett, C.A. (1989). Behaviour of the genus Papio: ethogram, taxonomy, methods and comparative measures. - In: Perspectives in primate biology, Vol. 3. (P.K. Serh \& S. Serh, eds). Today and Tomorrow's Printers and Publishers, New Delhi, p. 117-140.

Cords, M. (1987). Mixed-species association of Cercopithecus monkeys in the Kakamega Forest, Kenya. - Univ. Calif. Publ. Zool. 117, p. 1-109. 
- (1988). Mating systems of forest guenons: a preliminary review. - In: A primate radiation: Evolutionary biology of the African guenons (A. Gautier-Hion, F. Bourliere, J.P. Gautier \& J. Kingdon, eds). Cambridge University Press, Cambridge, p. 323-339.

- - (1990). Vigilance and mixed-species association of some East African forest monkeys. - Behav. Ecol. Sociobiol. 26, p. 297-300.

Dunbar, R.I.M. (1988). Primate social systems. - Croom Helm, London.

- - \& Sharman, M. (1984). Is social grooming altruistic? - Z. Tierpsychol. 64, p. 163-173.

Gautier-Hion, A., Quris, R. \& Gautier, J.P. (1983). Monospecific us polyspecific life: a comparative study of foraging and antipredatory tactics in a community of $\mathrm{Cer}$ copithecus monkeys. - Behav. Ecol. Sociobiol. 12, p. 325-335.

Goosen, C. (1981). On the function of allogrooming in Old-World monkeys. - In: Primate behavior and sociobiology. (A.B. Chiarelli \& R.S. Corrucaini, eds). Springer, Berlin, p. 110-120.

GreEnberG, L.D. (1970). Nutritional requirements of macaque monkeys. - In: Feeding and nutrition of nonhuman primates. (R.S. Harris, ed.). Academic Press, New York, p. 117-142.

Hart, B.L., Hart, L.A., Mooring, M.S. \& Olubayo, R. (1992). Biological basis of grooming behaviour in antelope: the body-size, vigilance and habitat principles. Anim. Behav. 44, p. 615-631.

Hemelrijk, C.K. (1994). Support for being groomed in long-tailed macaques, Macaca fascicularis. - Anim. Behav. 48, p. 479-481.

IsBell, L.A. \& Young, T.P. (1993). Social and ecological influences on activity budgets of vervet monkeys, and their implications for group living. - Behav. Ecol. Sociobiol. 32, p. 377-385.

Kurland, J.A. (1977). Kin selection in the Japanese monkey. -- Contributions to primatology. Vol. 12. S. Karger, Basel.

Leland, L. \& Struhskaer, T.T. (1993). Teamwork tactics. - Natural History 4, p. 43-48.

Lima, S.L. \& Dill, L.M. (1990). Behavioral decisions made under the risk of predation: a review and prospectus. - Can. J. Zool. 68, p. 619-640.

LindBerG, D.G. (1973). Grooming behavior as a regulator of social interactions in rhesus monkeys. - In: Behavioral regulators of behaviour in primates (C.R. CARPEnTER, ed.). Bucknell University Press, Lewisburg, PA, p. 124-148.

Maestripieri, D. (1993). Vigilance costs of allogrooming in macaque mothers. - Amer. Nat. 141, p. 744-753.

Muroyama, Y. (1994). Exchange of grooming for allomothering in female patas monkeys. - Behaviour 128, p. 103-119.

Rose, L.M. \& Fedigan, L.M. (1995). Vigilance in white-faced capuchins, Cebus capucinus, in Costa Rica. - Anim. Behav, 49, p. 63-70.

Schaub, H. (1994). Food-sharing experiments on long-tailed macaques. - Ph.D. thesis, University of Zürich.

Schino, G., Scucchi, S., Maestripieri, D. \& Turillazzi, P.G. (1988). Allogrooming as a tension-reduction mechanism: a behavioral approach. - Amer. J. Primatol. 16, p. 43-50.

Seyfarth, R.M. \& Cheney, D.L. (1984). Grooming, alliances and reciprocal altruism in vervet monkeys. - Nature 308, p. 541-543.

Siegel, S. \& Castellan, N.J.Jr. (1988). Nonparametric statistics. - McGraw Hill, New York.

SILK, J.B. (1982). AItruism among female Macaca radiata: explanations and analysis of patterns of grooming and coalition formation. - Behaviour 79, p. 162-188.

- - (1987). Social behavior in evolutionary perspective. - In: Primate societies. (B.B. Smuts, D.L. Cheney, R.M. Seyfarth, R.W. Wrangham \& T.T. Struhsaker, eds). University of Chicago Press, Chicago, p. 318-329. 
Stammbach, E. \& Kummer, H. (1982). Individual contributions to a dyadic interaction: an analysis of baboon grooming. - Anim. Behav. 30, p. 964-971.

Struhsaker, T.T. \& Leakey, M. (1990). Prey selectivity by crowned hawk-eagles on monkeys in the Kibale Forest, Uganda. - Behav. Ecol. Sociobiol. 26, p. 435-443.

Tanaka, I. \& Takefushi, H. (1993). Elimination of external parasites (lice) is the primary function of grooming in free-ranging Japanese macaques. - Anthropol. Sci. 101, p. 187-193. 